\title{
NOTA
}

\section{ENXERTIA PRECOCE DA NOGUEIRA-MACADÂMIA (1)}

\author{
FERNANDO ANTONIO CAMPO-DALL'ORTO $(2,4)$, MÁRIO OJIMA (2), \\ WILSON BARBOSA $(2,4)$, JOSÉ CARLOS SABINO $(3,4)$ e ORLANDO RIGITANO (2)
}

\begin{abstract}
RESUMO
A carência de mudas enxertadas de nogueira-macadâmia (Macadamia integrifolia Maid. e Bet.) constitui, ainda hoje, um dos grandes entraves ao efetivo estabelecimento da cultura nas condições brasileiras. Apesar dos recentes avanços técnicos conseguidos na sua propagação, o procedimento adotado à produção de mudas ainda demanda um periodo de dois a três anos, para sua efetiva instalação no campo. Neste trabalho, levado a efeito na Estação Experimental do Instituto Agronômico, em Tietê, SP, demonstrou-se a exeqüibilidade de produção de mudas de macadâmia, em tempo bem mais abreviado, isto é, apenas doze meses. O novo processo de obtenção de mudas precoces de macadâmia, sob ripado, pela enxertia de garfos pouco lignificados e protegidos com saquinhos plásticos, utilizando cavalos novos com cerca de seis meses de idade, além de possibilitar maior facilidade operacional e eficiência no pegamento dos enxertos, poderá propiciar a instalação do nogueiral com antecipação de cerca de um ano, em relação ao sistema corrente.
\end{abstract}

Termos de indexação: macadâmia, enxertia precoce, garfagem tipo "inglês-simples".

(1) Trabalho desenvolvido com recursos subsidiários do FINEP. Recebido para publicaçāo em 31 de março de 1987 e aceito em 21 de novembro de 1988.

(2 Seção de Fruticultura de Clima Temperado, Instituto Agronômico de Campinas (IAC), Caixa Postal 28, 13.001 Campinas (SP).

(3) Estação Experimental de Tietê, IAC.

(4) Com bolsa de pesquisa do CNPq. 
Um dos maiores entraves ao estabelecimento do cultivo comercial da nogueira-macadâmia nas condições brasileiras é a carência de material de propagação, como sementes para portà-enxerto e mudas enxertadas de alto padrão. No primeiro aspecto, o Instituto Agronômico tem procurado contornar essa deficiência, pelo fornecimento aos interessados de quantidades disponíveis de sementes e, posteriormente, garfos para enxertia dos cultivares mais indicados à formaçāo de plantas-matrizes de características agronômicas superiores. No segundo, desde a introduçāo da nogueira em 1948 (BITTENCOURT, 1965), o IAC tem-se empenhado no desenvolvimento de técnicas relativas ao aprimoramento dos métodos de propagação destinados a orientar viveiristas para a produção de boas mudas (OJIMA et al., 1976, 1984; CAMPO-DALL'ORTO et al., 1979).

Até há poucos anos, recomendava-se, com ênfase, a utilização de porta-enxertos vigorosos, bem enfolhados, com mais de $7 \mathrm{~mm}$ de diâmetro na regiáo do colo, isto é, a partir de dezoito meses de idade, a contar da semeadura. A enxertia era feita por garfagem, no topo da haste central, a cerca de $60 \mathrm{~cm}$ de altura, mantendo-se, no mínimo, dois a três pares de folhas abaixo do enxerto. Para sucesso da operação, tomava-se o cuidado de cobrir o garfo com um saquinho plásfico, a fim de protegê-lo contra a evaporação e insolação (OJIMA et al., 1984).

Apesar dos conhecimentos adquiridos com a propagação da nogueira, ao longo desses anos, outro fator negativo que tem dificultado sua implantação econômica em São Paulo reside no longo tempo exigido pela cultura para iniciar a frutificação (quatro-cinco anos). Isso é agravado pela relativa demora do método corrente adotado para a formação das mudas, o qual demanda de dois a três anos até o seu plantio definitivo no campo. Para contornar o problema, a execuçāo da enxertia no próprio vaso de semeadura, sob condições de ripado com $50 \%$ de luminosidade, já constitui procedimento de considerável avanço na produção de mudas de macadâmia (CAMPO-DALL'ORTO et al., 1979, e OJMA et al., 1984). Entretanto, o tempo gasto para formação de porta-enxertos de grande desenvolvimento, sem dúvida, caracterizava-se como fator extremamente limitante.

Na realidade, são ainda escassas as informaçōes sobre a propagação da nogueira-macadâmia em nossas condiçōes, o que impede uma recomendação mais racional na formação das mudas. $O$ presente trabalho foi idealizado com o objetivo de esclarecer certos aspectos práticos da enxertia, a fim de que se pudesse desenvolver um novo processso, mais rápido e de fácil formação de boas mudas da nogueira-macadâmia.

\section{Material e Métodos}

O experimento foi conduzido em ambiente de meia-sombra, no ripado da Estação Experimental de Tietê, do Instituto Agronômico. 
Os porta-enxertos utilizados eram constituidos, como é usual, de plântulas de uma mistura de cultivares de nogueira-macadâmia, formados por semeadura, nos próprios vasos plásticos de $30 \times 18 \mathrm{~cm}$. Por ocasiāo da enxertia (15-20 de julho de 1986), os dois grupos de porta-enxertos destinados à experimentaçāo contavam, respectivamente, com seis e vinte meses de idade, a partir da semeadura.

Como cultivares-copa utilizaram-se os dez seguintes: Keauhou (introdução havaiana), IAC Ti Campinas-B, 800 HAES (introdução), Keaumi (IAC 4-20), Keaudo (IAC 2-23), IAC Ti 3-4A, IAC Ti 1-21C, IAC Ti 4-12B, IAC 5-2 e IAC Ti 2-17D.

No experimento, procurou-se respeitar os requisitos considerados essenciais ao sucesso da enxertia de nogueira-macadâmia (OJIMA et al., 1984), com ênfase à escolha de porta-enxertos bem desenvolvidos e enfolhados e à coleta de garfos de ramos vigorosos, provenientes de plantas matrizes igualmente vigorosas e sadias. Para comparação, foram executados estes dois tratamentos de enxertia:

A - Garfagem, tipo "inglês-simples", no topo do porta-enxerto enfolhado (seis a oito folhas abaixo do ponto de enxertia), com vinte meses de idade (10-13mm de diâmetro na regiāo do colo), e com proteçāo do garfo $(10-13 \mathrm{~cm})$ com saco plástico transparente;

B - Garfagem tipo "inglês-simples", no topo do porta-enxerto enfolhado (duas a quatro folhas abaixo do ponto de enxertia), com seis meses de idade (menos de $5 \mathrm{~mm}$ na região do colo), e com proteção do garfo tenro $(7-10 \mathrm{~cm}) \mathrm{com}$ saco plástico transparente.

Efetuaram-se 25 enxertos por cultivar e por processo de enxertia, variando o calibre dos garfos com o dos porta-enxertos. Um mês após a enxertia, fez-se a retirada gradativa da proteção de saco plástico. A avaliação dos resultados da experimentação, em janeiro de 1987, consistiu na contagern dos enxertos em franco desenvolvimento. Assim, não se consideraram para efeito de pegamento os garfos com gemas dormentes ou com brotação deficiente.

Durante o transcorrer do ensaio, efetuaram-se irrigaçōes diárias por aspersão e pulverizaçōes mensais com o fungicida Maneb a $0,15 \%$ em mistura com o inseticida Metil-demeton a 0,10\% (OJIMA et al., 1986).

\section{Resultados e Discussão}

Conforme os dados do quadro 1, a garfagem tipo "inglês simples", executada no topo do porta-enxerto bem novo e tenro, com seis meses de idade, apresentou alta eficiência de pegamento (média de $94,8 \%$ ), superior ao processo corrente, ou seja, sobre o porta-enxerto com vinte meses $(66,8 \%)$. 
QUADRO 1. Pegamento dos enxertos de dez cultivares de nogueira-macadâmia, relativo a dois tratamentos de enxertia

\begin{tabular}{lcc}
\hline Cultivar - enxerto & $A\left({ }^{(1)}\right.$ & $B\left({ }^{1}\right)$ \\
\hline & $\%$ & $\%$ \\
Keauhou & 52 & $\ldots\left({ }^{2}\right)$ \\
IAC Ti Campinas-B & 56 & 96 \\
800 HAES & 56 & 92 \\
Keaumi (IAC 4-20) & 52 & 96 \\
Keaudo (IAC 4-23) & 76 & $\ldots$ \\
IAC Ti 3-4A & 36 & 100 \\
IAC Ti 1-21C & 88 & $\ldots$ \\
IAC Ti 4-12B & 80 & 92 \\
IAC 5-2 & 100 & 88 \\
IAC Ti 2-17D & 72 & 94,8 \\
\hline Média & 66,8 & \\
\hline$\left.{ }^{1}\right)$ A: Porta-enxertos convencionais, com vinte meses. B: Porta-enxertos precoces, com seis meses. \\
(2)... não determinado.
\end{tabular}

Nos dois tratamentos de enxertia, o crescimento dos enxertos, em seguida à retirada gradativa do saco plástico protetor, foi satisfatório. $\mathrm{Na}$ avaliação do ensaio, as mudas, tanto as enxertadas sobre porta-enxertos convencionais mais idosos quanto sobre os novos, respectivamente com 12 e 26 meses a partir da semeadura, encontravam-se em estádio de desenvolvimento apropriado para plantio no campo.

Observou-se que o porta-enxerto novo, fino e tenro e, conseqüentemente, o garfo também fino e pouco lignificado, possibilitou ao enxertador facilidades na escolha do material e no corte, resultando maior rendimento na operação de enxertia. Isso propiciou corte mais uniforme do material e melhor união do enxerto/porta-enxerto, o que teria influido decisivamente no melhor pegamento.

Os resultados obtidos tornam-se dos mais auspiciosos, uma vez que vêm corrigir os principais óbices ña prođução de mudas enxertadas de nogueira-macadâmia: demora de dois a três anos, escassez de garfos para enxertia com mais de $7 \mathrm{~mm}$ de diâmetro, e dificuldades na execução de cortes uniformes. $O$ sistema de porta-enxertos novos abrevia tal período para um ano, tornando-se bem maior a disponibilidade de garfos mais finos.

Acredita-se que a adoção desse sistema de enxertia precoce, com a formação mais rápida e eficiente de mudas, poderá agilizar o estabelecimento da cultura de nogueira-macadâmia em várias regiōes brasileiras. 


\section{SUMMARY}

\section{EARLY GRAFTING OF MACADAMIA-NUT SEEDLINGS}

The difficulty of obtainning good grafted seedlings has been a hindronce to establish commercial macadamia-nut orchards in Brazil. The current procedure takes from two to three years in the nursery for grafted macadamia to be transplanted in the field. This article reports an experiment where the grafting of macadamia seedlings raised in plastic bags was compared to the usual method of propagation. The results indicated the feasibility of making good one-year-old grafted macadamia-nut young trees.

Index terms: macadamia, precocious whip grafting.

\section{AGRADECIMENTO}

Os autores agradecem ao Sr. Benedito Nivaldo Antônio, funcionário da Estação Experimental de Tietê, a execução das enxertias.

\section{REFERÊNCIAS BIBLIOGRÁFICAS}

BITTENCOURT, P.V.C. Instruçōes preliminares para a cultura da nogueira-macadâmia. Campinas, Instituto Agronômico, 1965. 12p. (Boletim, 162)

CAMPO-DALL'ORTO, F.A.; OJIMA, M.; TOMBOLATO, A.F.C. \& RIGITANO, O. Desenvolvimento comparativo de algumas progênies de nogueira-macadâmia (Macadamia integrifolia Maiden e Betche) visando a obtenção de porta-enxertos. In: CONGRESSO BRASILEIRO DE FRUTICULTURA, 5., Pelotas, 1979. Anais. Pelotas, Sociedade Brasileira de Fruticultura, 1979. v.2, p.454-62.

OJIMA, M.; CAMPO-DALL'ORTO, F.A. \& RIGITANO, O. Germinação de sementes de nogueira-macadâmia. Campinas, Instituto Agronômico, 1976. 16p. (Boletim técnico. 33) mia. In: CAMPINAS. Instituto Agronômico. Instruçōes Agrícolas para o Estado de São Paulo. 4.ed. Campinas, 1987. p.129-30. (Boletim, 200)

; RIGITANO, O.; VEIGA, A.A.; SABINO,J.C.\&PINHEIRO, J. Propagação da nogueira-macadâmia - resultados experimentais de enxertia da nogueira-macadâmia no Instituto Agronômico de Campinas, SP. In: CONGRESSO BRASILEIRO DE FRUTICULTURA, 7., Florianópolis, 1983. Anais. Florianópolis, Sociedade Brasileira de Fruticultura, 1984. v.4, p.1038-1053. 